\title{
Bangladesh Journal of Orthodontics and Dentofacial Orthopedics Official Publication of Bangladesh Orthodontic Society.
}

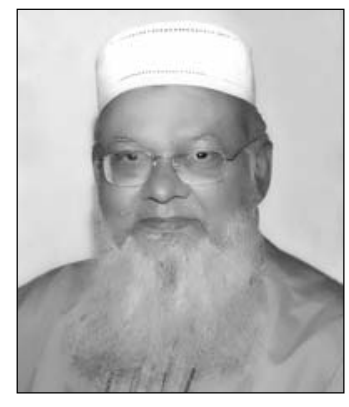

\section{Message}

President,

Bangladesh Orthodontic Society \&

Chairman, Journal Committee.

In a fast globalizing world today, it needs special efforts to publish a standard Journal on Orthodontics and Dento-facial Orthopedics. I have no doubt that this Journal will be a mile stone for better sharing of orthodontic education, research and techniques in our country.

I would also expect my fellow members to support by contributing their orthodontic and allied scientific articles for continuous publication of this scientific Journal, which will in turn upgrade orthodontic education and research, and treatment delivery in Bangladesh parallel to the international arena of orthodontics. Successful publication of this Journal will help us all to be inspired, well informed, caring, valued and responsible in our work and will help to ensure that the specialty of orthodontics continues to grow and flourish in the days ahead.

Special thanks to the Journal Committee and the valuable contributors for the most fascinating papers. My special thanks to Prof. Md. Zakir Hossain for his efforts to publish this journal. I hope this will be a continuous process.

Prof. (Dr.) Mohammad Emadul Haq

BDS (Dhaka), D. Orth, RCS (England), FCPS.Hon, FICD

President

Bangladesh Orthodontic Society

\&

Chairman, Journal Committee. 